\title{
COMUNICAÇÃO
}

\section{METODOLOGIAS DE INOCULAÇÃO DE Rhizoctonia solani NA CULTURA DA CENOURA ${ }^{1}$}

\author{
Inoculation methodology of Rhizoctonia solani in carrot \\ Amanda Cabral Corrêa de Oliveira ${ }^{2}$, Paulo Estevão de Souza³ ${ }^{3}$ Edson Ampélio Pozza ${ }^{3}$, \\ Felipe de Carvalho Manerba ${ }^{4}$, Maurício Ferreira Lopes ${ }^{4}$
}

\begin{abstract}
RESUMO
Rhizoctonia solani pode causar diferentes tipos de doenças em cenoura (Daucus carota L.). Para a avaliação de métodos de controle geralmente se utiliza inoculação artificial. Objetivou-se neste trabalho, ajustar uma concentração de inóculo de $R$. solani (AG-4) no cultivo de cenoura. Utilizou-se delineamento experimental em blocos ao acaso, com 5 repetições sendo a unidade experimental um vaso de $3 \mathrm{~L}$ com 40 sementes. Como substrato, utilizou-se solo/areia (3:1). Os tratamentos em esquema fatorial 4 × 3 sendo, 4 densidades de inóculo $\left(9 ; 18 ; 36 ; 72 ; \mathrm{mg}\right.$ de inóculo $\mathrm{kg}^{-1}$ de solo) e 3 métodos de infestação artificial (incorporados a todo o solo; incorporados na superfície; contato direto com as sementes) e uma testemunha adicional. O experimento foi conduzido em câmara de crescimento a $20^{\circ} \mathrm{C}$, com fotoperíodo de $12 \mathrm{~h}$. As avaliações foram realizadas diariamente do $8^{\circ}$ ao $30^{\circ}$ dia após a semeadura, registrando-se o estande e o número de plântulas com tombamento. Analisou-se o índice de velocidade de emergência, porcentagem média de tombamento pré e pós emergência. A densidade de $72 \mathrm{mg}$ de inóculo $\cdot \mathrm{kg}^{-1}$ de solo incorporado na superfície foi o método mais eficiente.
\end{abstract}

Termos para indexação: Daucus carota, inóculo, epidemiologia.

\begin{abstract}
Rhizoctonia solani may cause different diseases in carrot (Daucus carota L.). To test control methods, artificial inoculation is generally employed. This work aimed to adjust a methodology to inoculate $R$. solani (AG-4) in carrot. A randomized block outline with five replicates was used, with an experimental unit of a 3L-pot with 40 seeds and a substact composed by a mixture of soil/sand $(3: 1 \mathrm{v} / \mathrm{v})$. Treatments were those in a factorial experiment $4 \mathrm{x} 3$, with 4 inoculum densities $\left(9 ; 18 ; 36 ; 72 \mathrm{mg}\right.$ of inoculum. $\left.\mathrm{kg}^{-1} \mathrm{of} \mathrm{soil}^{\mathrm{j}}\right)$ and three forms of artificial infestation (incorporated to the substract as a whole; incorporated on the surface; with direct contact with seeds) and an additional control. The experiment was carried out in a growth chamber at $20^{\circ} \mathrm{C}$ and a $12 \mathrm{~h}$ photoperiod. The evaluations were daily performed from the 8 th to the 30 th day after sowing, recording plant stand and number of seedlings with damping-off. The emergence index, averge percentage of pre and post emergence. Were analyzed the density of $72 \mathrm{mg}$ of inoculum. $\mathrm{kg}^{-1} \mathrm{of} \mathrm{soil,}$ incorporated on the surface of the susbtract was the most efficient inoculation method.
\end{abstract}

Index terms: Daucus carota, inoculum, epidemiology.

(Recebido em 9 de março de 2006 e aprovado em 12 de junho de 2007)

A cenoura (Daucus carota L.) é considerada suscetível à infecção por Rhizoctonia solani Kühn, entretanto, não existem registros quantitativos das perdas. Também não se conhecem cultivares resistentes ao tombamento de plântulas, em razão, principalmente, do complexo de patógenos envolvidos na ocorrência da doença (HENZ \& LOPES, 2000). A planta é suscetível, durante todo o ciclo da cultura, apresentando sintomas desde o tombamento, até a podridão da coroa e o cancro da raiz. No Brasil, são escassos os trabalhos sobre o patossistema R. solani e cenoura. Tendo-se como referência trabalhos realizados com outras culturas e/ou em outros países, sob condições edafo-climáticas diferentes das predominantes nas regiões produtoras de cenoura no Brasil, implicando em desconhecimento da biologia e da ecologia do patógeno, aspecto importante para embasar

1Parte da dissertação do curso de mestrado em agronomia (Fitopatologia), Departamento de Fitopatologia/DFP - Universidade Federal de Lavras/UFLA Cx. P. 3037 - 37200-000 - Lavras, MG.

${ }^{2}$ Mestre - Departamento de Fitopatologia/DFP - Universidade Federal de Lavras/UFLA - Cx. P. 3037 - 37200-000 - Lavras, MG - amandacco@hotmail.com Bolsista do CNPq

${ }^{3}$ Doutor, Professor - Departamento de Fitopatologia/DFP - Universidade Federal de Lavras/UFLA - Cx. P. 3037 - $37200-000$ - Lavras, MG - pauleste@ufla.br; eapozza@ufla.br

${ }^{4}$ Graduando-Departamento de Fitopatologia/DFP-Universidade Federal de Lavras/UFLA-Cx. P. 3037-37200-000-Lavras, MG-mauricio@agronomo.eng.br; felipemanerba@hotmail.com 
estudos sobre medidas de manejo (MICHEREFF FILHO et al., 1996).

Vários fatores podem influenciar o progresso de doenças, entre eles a temperatura, a umidade do solo e a concentração de inóculo. A inoculação eficiente de um patógeno é fundamental para avaliar métodos de manejo, cultivares resistentes e fungicidas aplicados no controle de doenças.

Algumas metodologias são empregadas na tentativa de multiplicar $R$. solani artificialmente. O inóculo é cultivado em substrato como arroz (MICHEREFF et al., 1996), aveia (GOULART, 2002) e outros que apresentam diferentes tempos para colonização, secagem, armazenagem e viabilidade do inóculo. Os estudos também apresentaram modificações na forma de inoculação no solo, diferindo nas densidades de inóculo e na distância do inóculo à semente (MICHEREFF FILHO et al., 1996). Esses autores observaram que concentrações de inóculo entre 50 a $300 \mathrm{mg} \cdot \mathrm{kg}^{-1}$ de solo favoreciam o aumento da incidência do tombamento de plântulas de feijão, principalmente com o aumento da concentração do inóculo, assim como a proximidade do inóculo das sementes aumentava a severidade da doença. Por sua vez, Santos et al. (2005), utilizando a mesma metodologia para a produção do inóculo em grãos de arroz, em estudos para feijoeiro e algodoeiro, encontraram doses satisfatórias em 72 e $144 \mathrm{mg} \cdot \mathrm{kg}^{-1}$ de substrato. Entretanto, os autores utilizaram substrato autoclavado.

Diante disso, objetivou-se ajustar uma concentração de inóculo de $R$. solani em substrato para estudos de tombamento em plântulas de cenoura (Daucus carota L.).

Sementes de cenoura da cultivar Juliana foram analisadas quanto à qualidade sanitária e fisiológica inicial do lote de acordo com testes indicados nas Regras para Análise de Sementes (BRASIL, 1992). Estas foram semeadas em sulcos de $2 \mathrm{~cm}$ de profundidade em vasos plásticos de 3 litros, contendo o substrato solo/areia (3:1), não esterilizado. Os vasos no plantio foram regados com $695 \mathrm{~mL}$ de água e recarga de $86 \mathrm{~mL}$, a cada 2 dias. O isolado de $R$. solani, pertencente ao grupo de anastomose 4 (AG4), foi obtido de raízes tuberosas de cenoura, com sintomas de cancro de raiz, procedente de plantio comercial do município de São Gotardo, MG. O preparo do inóculo foi feito pela metodologia descrita por Michereff Filho et al. (1996) com modificações. O inóculo foi obtido a partir de culturas com cinco dias de idade, crescidas em meio BatataDextrose-Ágar (BDA), sob regime de luz contínua e temperatura de $20^{\circ} \mathrm{C}$. Três discos de meio de cultura $(9 \mathrm{~mm}$ de diâmetro) contendo micélio do patógeno foram transferidos, em ambiente asséptico, para sacos de polietileno de $10 \times 17 \mathrm{~cm}$ contendo $60 \mathrm{~g}$ de arroz pré-cozido e autoclavado $\left(120^{\circ} \mathrm{C}, 30 \mathrm{~min}, 1 \mathrm{~atm}\right)$, incubados por 8 dias, em fotoperíodo de 12 horas a $20^{\circ} \mathrm{C} . \mathrm{O}$ arroz colonizado foi acondicionado em saco de papel e seco à sombra, em temperatura ambiente por 96 horas. Posteriormente, esse inóculo constituído de arroz e $R$. solani foi triturado em multiprocessador, peneirado em malha de $0,180 \mathrm{~mm}$ e armazenado em saco plástico fechado.

Os tratamentos basearam-se nas densidades de inóculo de 9, 18, 36 e $72 \mathrm{mg}$ de inóculo por $\mathrm{kg}$ de solo, com três métodos de infestação artificial do solo: inóculo misturado a $100 \%$ do solo que preenchia os vasos (semelhante à infecção natural); inóculo incorporado a $10 \%$ de solo, na parte superior do vaso e inóculo adicionado em contato direto com as sementes, antes do plantio (caracterizando sementes infestadas). A testemunha consistiu do plantio de sementes em solo não infestado. $\mathrm{O}$ experimento foi conduzido em câmara de crescimento a $20^{\circ} \mathrm{C}$, com fotoperíodo de 12 horas.

O delineamento experimental utilizado no ensaio foi o de blocos ao acaso, com esquema fatorial de 4 × 3 (4 densidades e 3 métodos de aplicação) +1 tratamento adicional, a testemunha, com 5 repetições, sendo a unidade experimental um vaso com 40 sementes.

Avaliaram-se a emergência e o tombamento de plântulas, por meio de inspeções diárias, do oitavo ao trigésimo dia após a semeadura. Para análise dos dados, foi calculado o índice de velocidade de emergência (IVE), calculado pela fórmula proposta por Maguire (1962), sendo: $\mathrm{IVE}=\sum_{\mathrm{i}=1}^{\mathrm{n}} \mathrm{N}_{\mathrm{i}} / \mathrm{Di}, \mathrm{N}_{\mathrm{i}}=$ número de plântulas germinadas na $1^{\mathrm{a}}$ contagem, $2^{\mathrm{a}}$ contagem, ... enésima contagem, respectivamente; $\mathrm{D}_{\mathrm{i}}=$ número de dias após semeadura na $1^{\mathrm{a}}$ contagem, $2^{\mathrm{a}}$ contagem, ... enésima contagem, respectivamente; porcentagem de tombamento pósemergência (\%TPÓS), onde: \%TPÓS $=\left(100 \times \mathrm{N}_{\mathrm{t}}\right) / \mathrm{X}_{\mathrm{et}}, \mathrm{N}_{\mathrm{t}}=$ número de plantas tombadas; $\mathrm{X}_{\mathrm{et}}=$ média de plântulas emergidas na testemunha; e, por transformação, a porcentagem de plântulas tombadas em pré-emergência (\%TPRÉ), onde: \%TPRÉ $=\left[\left(40-\mathrm{N}_{\mathrm{e}}\right) \times\left(\% \mathrm{X}_{\mathrm{et}}\right)\right] / 100,40=$ constante, correspondente ao número de sementes por vaso; $\mathrm{N}_{\mathrm{e}}=$ número final de plântulas emergidas; $\% \mathrm{X}_{\mathrm{et}}=$ porcentagem da média de plântulas emergidas na testemunha.

As análises estatísticas foram realizadas utilizandose o programa Sisvar ${ }^{\circledR}$ (FERREIRA, 2000). As variáveis significativas no teste $\mathrm{F}$ foram submetidas ao teste de médias ou análise de regressão. O índice de velocidade de emergência e o tombamento médio de pré-emergência foram comparados pelo teste de Tukey ( $\mathrm{P} £ 5 \%$ ). Para a porcentagem média de pós-emergência foram analisadas densidades entre métodos de aplicação ajustando-se modelos linear e quadrático. 
Para confirmar a identidade do patógeno, plântulas com sintomas de tombamento foram submetidas ao isolamento em meio Ágar-Água para posterior análise morfológica.

A análise fisiológica e sanitária do lote de sementes não detectou $R$. solani e registrou $81 \%$ de emergência. As sementes apresentaram alto vigor, pois $70 \%$ dessa emergência ocorreu nos primeiros 7 dias da montagem dos 'Blotter test'.

Os métodos de aplicação tiveram efeito significativo de $\mathrm{P}=0,8672$, assim como a testemunha diferiu dos tratamentos com $\mathrm{P}=0,9619$ para índice de velocidade de emergência. A quantidade de inóculo não teve influência significativa na emergência das plântulas. O inóculo adicionado à semente diferiu significativamente dos métodos de aplicação do inóculo adicionado a $100 \%$ e $10 \%$ do solo, na superfície, com a menor velocidade de emergência média de 3,18 (Tabela 1).

Tabela 1 - Dados médios de índice de velocidade de emergência (IVE), tombamento médio de pré (\%TPRÉ) e pós-emergência (\%TPÓS) de plântulas de cenoura submetida a três métodos de aplicação do inóculo de Rhizoctonia solani AG-4. UFLA, Lavras, MG, 2006.

\begin{tabular}{|c|c|c|c|}
\hline Formas aplicação & IVE & \% TPRÉ & \% TPÓS \\
\hline $\begin{array}{l}\text { Inóculo adicionado } \\
\text { a } 100 \% \text { do solo }\end{array}$ & $11,76 \mathrm{a}$ & $15,75 b$ & $28,21 \mathrm{~b}$ \\
\hline $\begin{array}{l}\text { Inóculo adicionado } \\
\text { a } 10 \% \text { do solo na } \\
\text { superfície }\end{array}$ & $12,10 \mathrm{a}$ & $20,45 \mathrm{~b}$ & $44,64 \mathrm{a}$ \\
\hline $\begin{array}{l}\text { Inóculo adicionado } \\
\text { as sementes }\end{array}$ & $3,18 \mathrm{~b}$ & $48,13 \mathrm{a}$ & $27,86 \mathrm{ab}$ \\
\hline testemunha & $7,52 *$ & $21,00 *$ & $0,0 *$ \\
\hline
\end{tabular}

Médias com mesma letra não diferem entre si pelo teste de Tukey (Pd'0,05).

* Significativo ( $\mathrm{P}=0,0463)$ Para a variável porcentagem de plântulas com tombamento em pré-emergência, avaliando os métodos de aplicação do inóculo, adicionado a $100 \%$ e a $10 \%$ do solo, na superfície, foram mais eficientes, diferindo estatisticamente do inóculo adicionado às sementes, que apresentou 48,13\% de plântulas tombadas em pré-emergência (Tabela 1).

Para a variável porcentagem de plântulas com tombamento em pré-emergência, os métodos de aplicação do inóculo, adicionado a $100 \%$ e a $10 \%$ do solo, na superfície, foram mais eficientes, diferindo estatisticamente do inóculo adicionado às sementes, que apresentou 48,13\% de plântulas tombadas em pré-emergência (Tabela 1).
Para porcentagem média de tombamento de pósemergência, houve efeito na interação entre densidade de inóculo e método de aplicação $\mathrm{P}=0,9574$. Os modelos quadráticos e linear foram os de melhor ajuste para o inóculo adicionado a 100 e $10 \%$ do solo, respectivamente. Não houve ajuste de modelos polinomiais para o método de aplicação do inóculo adicionados às sementes (Figura 1).

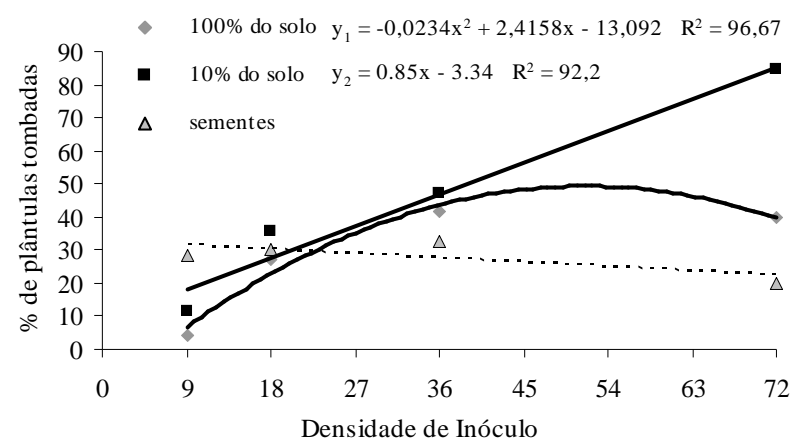

Figura 1 - Porcentagem média de tombamento pósemergência de plântulas de cenoura inoculadas com Rhizoctonia solani AG-4, em quatro densidades de inóculo, por três métodos de aplicação. UFLA, Lavras, MG, 2006.

O método de aplicação do inóculo adicionado às sementes diferiu dos aplicados ao solo, tanto no índice de velocidade de emergência quanto na porcentagem média de tombamento de pré-emergência, em conseqüência da maior proximidade do inóculo de $R$. solani ao hospedeiro. $O$ fato das sementes estarem semeadas a $2 \mathrm{~cm}$ de profundidade também influenciou na intensidade da doença, impedindo a emergência. Relatos da distância e da profundidade do inóculo em relação ao hospedeiro confirmam os resultados encontrados: quanto mais próximo da semente, mais severa a infecção (DIMOND \& HORSFALL, 1965, citados por MICHEREFF FILHO et al., 1996). A semente na fase de germinação absorve maior quantidade de água e seus tecidos ficam tenros, liberando nutrientes que estimulam os microrganismos da rizosfera. Nesta circunstância, há uma maior probabilidade de penetração e colonização do patógeno, ocasionando a podridão de pré-emergência (VALE et al., 2001).

Em estudos realizados por Michereff Filho et al. (1996), para a cultura do feijão, o aumento da intensidade da doença de 32,4 a 84,4\%, foi diretamente proporcional ao incremento na densidade de inóculo, de 50 até $300 \mathrm{mg} \cdot \mathrm{kg}^{-1}$ de solo, enquanto que em plântulas de cenoura, apenas 72 $\mathrm{mg} \cdot \mathrm{kg}^{-1}$ de solo causou $84,29 \%$ de tombamento em pós- 
emergência. Essa baixa densidade de inóculo, capaz de causar tombamento em cenoura, é fator preocupante no campo, quando se associa a condições edafo-climáticas ideais e/ou rotação de culturas suscetíveis ao patógeno.

Em outro trabalho desenvolvido com algodão e feijão, por Santos et al. (2005), a densidade de inóculo suficiente para causar sintomas diferenciados entre os tratamentos foi de 72 e $144 \mathrm{mg} \cdot \mathrm{kg}^{-1}$ de substrato, respectivamente, causando entre 40 e $50 \%$ de intensidade de doença, sendo quantidades de inóculo semelhantes à necessária para causar $84,29 \%$ de tombamento em cenoura. Entretanto, os autores utilizaram solo autoclavado, sem a microbiota que poderia competir com o inóculo, e dessa forma as densidades de inóculo foram inferiores às citadas por Michereff Filho et al. (1996).

A variável porcentagem média de tombamento de pós-emergência foi a mais eficiente para avaliar a doença na cultura da cenoura, justificando-se pelo fato das plântulas serem suscetíveis ao patógeno e, portanto, seus tecidos foram completamente lesionados, permitindo apenas avaliações da incidência da doença. Também por esse motivo, não foi possível avaliar a severidade da doença, utilizando-se escala de notas, conforme o tamanho da lesão formada no hipocótilo das plântulas como avaliase em plântulas de feijão e algodão (MICHEREFF FILHO et al., 1996; SANTOS et al., 2005). Outro fator importante na escolha da porcentagem média de tombamento de pósemergência, é que as sementes de cenoura são pequenas, dificultando sua recuperação para avaliação precisa do percentual de tombamento de pré-emergência.

É importante considerar, como metodologia para trabalhos na cultura da cenoura, que o melhor resultado não foi o capaz de infectar o maior número de sementes e sim o que causou maior número de tombamento de plântulas em pós-emergência. Isso porque a morte de todas as plântulas não permitiria a comparação visual dos resultados. Dentre as metodologias de inoculação testadas, $72 \mathrm{mg}$ de inóculo, quando aplicada a $10 \%$ do substrato do vaso na camada de 0 a $2 \mathrm{~cm}$, permitiu observar a máxima porcentagem de tombamento de plântulas em pós emergência de cenoura. Assim, essa metodologia pode ser considerada suficiente para estudos de tombamento por $R$. solani em cenoura na fase de plântula.

\section{REFERÊNCIAS BIBLIOGRAFICAS}

BRASIL. Ministério da Agricultura e Reforma Agrária. Regras para análise de sementes. Brasília, DF, 1992. 365 p.

FERREIRA, D. F. Análises estatísticas por meio do SISVAR para Windows versão 4.0. In: REUNIÃO ANUAL DA REGIÃO BRASILEIRA DA SOCIEDADE INTERNACIONAL DE BIOMETRIA, 45., 2000, São Carlos, SP. Programa e Resumos... São Carlos: UFSCar, 2000. p. 235.

GOULART, A. C. P. Efeito do tratamento de sementes de algodão com fungicidas no controle do tombamento de plântulas causado por Rhizoctonia solani. Fitopatologia Brasileira, Brasília, v. 27, n. 4, p. 399-402, jul./ago. 2002.

HENZ, G. P.; LOPES, C. A. Doenças das Apiáceas. In: ZAMBOLIM, L.; VALE, F. X. R.; COSTA, H. Controle de doenças de plantas: hortaliças. Viçosa: UFV, 2000. v. 2, p. 447-450.

MAGUIRE, J. D. Speed of germination-aid in selection and evaluation for seedling emergence and vigour. Crop Science, Madison, v. 2, n. 2, p. 176-177, Mar./Apr. 1962.

MICHEREFF FILHO, M.; MICHEREFF, S. J.; SILVA, E. B.; ANDRADE, D. E. G. T.; ANTUNES SOBRINHO, S.; NORONHA, M. A.; MARIANO, R. L. R. Influência de tipos de solo do estado de Pernambuco na intensidade da doença induzida por Rhizoctonia solani em feijoeiro. Fitopatologia Brasileira, Brasília, v. 21, n. 1, p. 19-25, mar. 1996.

SANTOS, F. S.; SOUZA, P. E.; OLIVEIRA, C. A.; MAGALHÃES, F. H. L.; LAURENTI, M. A. Ajuste do inóculo de Rhizoctonia solani em substrato para estudos de Rizoctoniose em algodoeiro e feijoeiro. Summa Phyitopathologica, Botucatu, v. 31, n. 4, p. 373-375, 2005.

VALE, F. X. R. do; ZAMBOLIM, L.; JESUS JÚNIOR, W. C. de; VIDA, J. B. Importância do manejo integrado de doenças. In: SILVA, L. H. C. da; CAMPOS, J. R.; NOJOSA, G. B. de A. (Eds.). Manejo integrado de doenças e pragas em hortaliças. Lavras: UFLA, 2001. p. 39-90. 